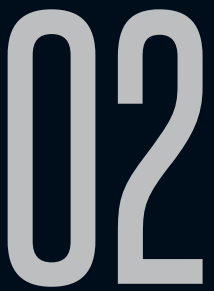

\title{
TERRITÓRIOS DA FICÇÃO FANTÁSTICA. ROSALBA CAMPRA. 2016.
}

Rita de Cássia Silva Dionísio Santos

Recebido em 07 out 2017. Rita de Cássia Silva Dionísio Santos é Doutora Aprovado em 17 out 2017. em Literatura pela Universidade de Brasília-UnB (2011); mestre em Letras: Estudos Literários pela Universidade Federal de Minas Gerais-UFMG (2005). Professora nos cursos de Graduação em Letras, na Pós-Graduação em Letras/Estudos Literários e no Mestrado Profissional em Letras em Rede Nacional (PROFLETRAS) da Universidade Estadual de Montes Claros-UNIMONTES. Faz parte do Grupo de Pesquisas em Estudos Literários-GEL da Unimontes e do Grupo de Trabalho Vertentes do Insólito Ficcional, da Associação Nacional de Pós-Graduação e Pesquisa em Letras e Linguística-ANPOLL. Membro do Grupo de Pesquisa Produções Literárias e Culturais para Crianças e Jovens (FFLCH-USP/CNPq). Atua principalmente nos seguintes temas: Literatura Brasileira, Literatura Brasileira Contemporânea, Literatura Comparada, Insólito ficcional, Literatura de Minas Gerais, Escritoras de Minas Gerais, Literatura infantojuvenil, Leitura do texto literário e formação do leitor, Formação docente. CV Lattes: http://lattes.cnpq.br/0886864680892636 E-mail: cassiadionisio@hotmail.com 
A obra Territórios da ficção fantástica, de Rosalba Campra, é uma versão em português do espanhol Territórios de la fición: lo fantástico (2008) - que fora publicada originalmente em italiano, com o título Territori della finzione: il fantástico nella literatura (2000). Natural de Córdoba, na Argentina, onde estudou Letras na Universidad Católica, Campra especializou-se em Teatro e Cinema nas

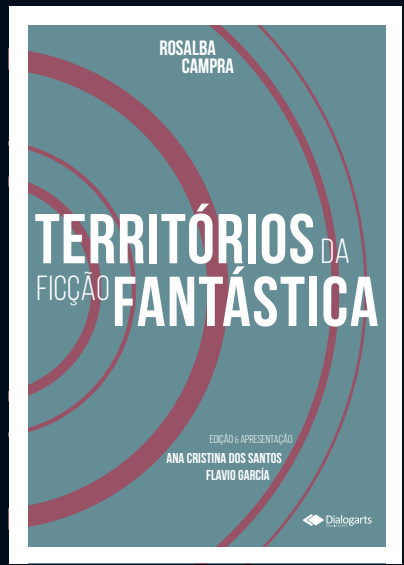
universidades francesas de Nancy e Paris VIII. Em La Sapienza, na Universidade de Roma I, a autora obteve o título de doutoramento, com tese sobre a contística de Julio Cortázar. Com alentada obra, que inclui teoria, crítica e ficção, Rosalba Campra se aposentou como Professora Catedrática de Literatura Hispano-Americana de La Sapienza, onde dedicou grande parte de seus estudos à ficção fantástica. Ministrou cursos em diversas universidades nas Américas e na Europa. É autora de "Como con bronca y junando", La retórica del tango (1996), Cortázar para cómplices (2009) e Zona de juego (2014), entre outros.

A apresentação do livro, de autoria dos pesquisadores Ana Cristina dos Santos e Flavio García (ambos da Universidade do Estado do Rio de Janeiro), explicita a dinâmica de sua tradução e edição, incluindo dados e informações sobre a atenção requerida na seleção vocabular e no uso dos termos teóricos, por exemplo, com o objetivo que as discussões empreendidas sejam eficazmente realizadas pelo público de leitores de língua portuguesa.

Segmentada em sete capítulos - os quais se subdividem em 
subcapítulos - Territórios da ficção fantástica encerra, como objetivo primordial, o propósito de "identificar uma possível estratégia de leitura do insólito ficcional que sirva para a análise e a escrita do fantástico" (SANTOS; GARCIA, 2016). Como metodologia para colocar à mostra o seu conjunto de conceitos e os argumentos que os fundamentam, Campra apresenta, no incipit de cada uma das partes, após o título do subcapítulo, uma ementa composta por frases nominais, não raro, pontuadas com interrogações - aspecto, aliás, que sugere o movimento refletir/inquirir no qual o leitor se vê enredado neste texto preciso, lúcido e, sem dúvida, fulcral para os estudos contemporâneos sobre o insólito.

O capítulo um, "Um território instável", discute a "verdade" da narrativa, o caráter "imaginário", "não real", atribuído ao fantástico, se seria possível o reconhecimento do fantástico pelos seus temas e quais seriam esses temas. Na página 27, argumenta Campra (2016):

O fantástico pressupõe, empiricamente, o conceito de realidade, que se dá como indiscutível, sem necessidade de demonstração: simplesmente é. Deve-se reconhecer, entretanto, que a relação entre os dois termos não implica a simetria existente entre eles. Na edição do Petit Larousse, de 1926, por exemplo, o "fantástico" tem como antônimo o "real", mas como antônimo de "real" não aparece "fantástico", mas "imaginário falso". [...] O problema se torna mais complexo quando essas categorias, dos dicionários gerais, passam para o mundo da narrativa, por exemplo. O que elas querem dizer quando são aplicadas a um universo que por definição não é "real", mas "ficcional"?

Nessa mirada, a estudiosa esclarece que, na maioria dos casos, esses termos julgam o grau de adequação dos textos ao mundo 
extratextual (a experiência do mundo extratextual que o leitor aceita) - mas que não costumam definí-los. O fantástico, assim contemplado, não seria mais que um dos lados, desconhecidos ou negados, da realidade (p.28).

Em "Fantasmas e afins. Mais uma classificação", Campra propõe que os temas do fantástico sejam classificados segundo duas classes: as "categorias substantivas" e as "categorias predicativas", as quais, diferentemente das sistematizações propostas por Todorov e Barrenechea, por exemplo, considera mais homogêneas, e que, individualmente ou combinadas em maior ou menor grau de complexidade, permitiriam abranger a constelação de motivos que constituem o nível semântico do texto. Discorrendo a respeito do caráter transgressor do fantástico e sobre as "inesgotáveis possibilidades dessa transgressão" (p.53) e, ainda, da possibilidade de sobreposição e combinação desses motivos, com evidente perceptibilidade crítico-teórica, a autora expõe que o inventário elaborado nessas suas páginas não esgotaria o tema (p.66).

O capítulo três, "Em busca de provas", examina o problema da verossimilhança e da realidade como efeito. Todo texto ficcional solicita a credulidade do leitor - ou, melhor, a sua cumplicidade, o reconhecimento da "verdade" de sua ficção. Contudo, lembra Campra, o fantástico é, por definição, inverossímil. A verossimilhança, assim, não seria mais que um tipo de consenso, às vezes percebido com tal, às vezes não, de todos os modos, sujeito à mutabilidade histórica.

No capítulo quatro, "A arte de narrar", discorre-se sobre os limites da percepção - que distância existiria ente a realidade e os 
limites que a definem, por exemplo - a pluridiscursividade textual e os seus artifícios (narrador em primeira e em terceira pessoa), pondo em relevo a ideia de que a narrativa fantástica é um espaço de dúvidas e adverte-se que o "leitor experiente sabe que todo narrador é um trapaceiro" e que o "pacto que a voz narrante da ficção instaura com seu leitor não é inviolável" (p.107).

"Os desafios do silêncio" aduz aos vazios criados pela ausência de sequências conclusivas nos contos fantásticos, concretizados, entre outros, pelos sinais gráficos de reticências. Adverte-se que certos contos em que não há vampiros, fantasmas ou deslizamentos no tempo e no espaço são colocados pelo leitor no território do fantástico, porque se trataria de uma poética dos vazios, pois o que distinguiria o desenlace regressivo da narrativa fantástica de outros tipos de narrativas com enigma seria, propriamente, o seu caráter incompleto, múltiplo ou incerto: é na falta de resolução que o conto fantástico constrói o seu sentido (p.125).

No sexto capítulo, "Que falem os vampiros", Campra afirma que junto ao silêncio da voz narrante sobre a natureza dos fatos que narra (suas motivações, a própria existência desses fatos), manifesta-se outra classe de silêncio, de densidade e qualidade particular, de tal maneira solidificado no gênero que termina por parecer natural e necessário: o silêncio da criatura fantástica. Os textos em que o ponto de vista é invertido - em que aos vampiros se concede a voz - propõem uma espécie de vertigem que a literatura fantástica tradicional teria evitado. Nesse tipo de narrativa, contrária à poética dos vazios, não existiria o não dito. Os seres descrevem-se a si mesmos, fazendo com que o texto se inscreva nas margens do realismo - "se aceitarmos que o realismo 
significa, entre outras coisas, a existência de um paradigma em grau de explicar todo efeito por sua causa" - (p.170).

Em "Uma palavra em forma de armadilha", capítulo sete, Rosalba Campra refere-se à leitura como um fenômeno possível graças ao tempo - do leitor -, e à temporalidade que o texto estabelece. A ação de ler (especialmente a de ler ficções) estrutura o tempo como uma alternância entre a realização de esperas e tensões que supõem um compromisso de resolução, e o cumprimento desse compromisso - ou sua frustração. Nessa perspectiva, a autora lembra que Todorov destacara a impossibilidade (ou melhor, a impertinência) de uma leitura descontínua desse tipo de textos, identificando na organização sequencial do fantástico uma das razões de sua efetividade e, anuncia Campra, talvez seria essa uma das causas pelas quais - fantástico encontra sua dimensão privilegiada nas formas breves. Também neste capítulo, Campra declara que a passagem de um fantástico preponderantemente semântico, como o do século XIX, a um fantástico do discurso, como o que parece ter sido estabelecido a partir da segunda metade do século $X X$, está contígua a uma experimentação proveniente de uma consciência linguística que se manifesta, sobretudo, como autoquestionamento: “o texto que pensa por si próprio, que se contempla em sua condição de objeto criado pela escritura, que se propõe ao leitor como projeção da própria atividade" (p.191).

A recuperação histórica dos conceitos de fantástico, sua classificação, em perspectiva dialógica, de suas formas narrativas e temáticas e o exercício hermenêutico de exemplificar, didática e diligentemente, as afirmações que apresenta - entre outros 
aspectos aqui não desenvolvidos por uma questão de economia - validam a importância e imprescindibilidade desta obra para os atuais estudos sobre o gênero fantástico e seus desdobramentos. 